\title{
RELASI WAHYU DALAM TIGA AGAMA SAMAWI (KAJIAN TERHADAP PEMIKIRAN MOHAMMED ARKOUN)
}

\author{
Lutfi Maulida, Siti Nurmajah \\ STAI Pandanaran Yogyakarta \\ lutfimaulida012@gmail.com, sitinurmajah9@gmail.com
}

\begin{abstract}
The revelation so far is reading by partially and exclusively way. Partial and exclusive here means only discussing only the religious groups. Each religion has its own truth claims. In this point, Arkoun's idea about revelation found its signification. From his prespective which contemplate the revelation not only by Islamic view but also consider its relation to the two religion before Islam. This article aims to discuss the Arkoun's idea about revelation and how the implication of his idea to the multireligion discourse. The Abrahamic religion is Yahudi, Kristen, and Islam. Arkoun said that basically Yahudi, Kristen, and Islam are a social group which produce by the revelation. the dialogue between the divine religions can be opened and the exclusivity of reading the revelations can be eliminated through Arkoun's idea of revelation.
\end{abstract}

Keywords : Revelation, Three Religon of Revelation, Islamic Thought, Arkoun.

\section{Pendahuluan}

Diskursus mengenai wahyu se nantiasa menjadi topik bahasan yang menarik.Sebagai agama yang bera sal dari langit (agama samawi),ten tunya dalam Yahudi,Kristen,dan IsIslam,wahyu menjadi salah satu topik sentral dalam kepercayaan ketiganya. Meskipun sama-sama berasal dari wahyu Tuhan,namun ketiganya me ngonsepsikan wahyu secara berbeda. Seperti halnya Islam yang memiliki konsepsi sendiri mengenai wahyu, Kristen juga memiliki konsepsinya sendiri tentang wahyu, demikian pula dengan agama Yahudi.

Agama Yahudi hanya menga mbil kitab-kitab dari Perjanjian Lama namun tidak mempercayai kitab-kitab dari Perjanjian Baru karena mereka tidak percaya kepada Yesus Kristus sebagai pemenuhan Perjanjian Lama. Hal ini kita lihat misalnya pada kutipan yang diambil oleh Paus Benedict XVI dalam bukunya "Jesus of Nazareth,(UAS:Doubleday Publishing, 2007). Buku ini dikarang oleh
Rabbi Neusner,dalam sebuah imaji nasi dialog antara dirinya dengan seorang Rabbi kuno Yahudi tentang ajaran Yesus (Paus Benedictus XVI, Jesus of Nazareth, USA: 2007, hlm. 108-109). la membandingkan ajaran Yesus dengan teks Talmud Babylonia untuk mencari kebenaran Hukum Tuhan. Orang Kristen percaya bahwa wahyu Tuhan ada dalam diri dan pribadi Yesus Kristus itu sendiri. Sedangkan dalam Islam, wahyu adalah al-Qur'an, yakni Firman Allah yang disampaikan oleh Nabi $\mathrm{Mu}$ hammad.

Salah seorang pembaharu pemikiran Islam, Mohammed Arkoun, berpendapat bahwa Yahudi, Kristen, dan Islam merupakan kelompok masyarakat yang terbentuk dari Kitab dan diproduksi oleh dan atas dasar Kitab.la mengemukakan bahwa kunci dari revelations atau wahyu dalam hubungannya dengan tiga agama samawi ialah berasal dari berbagai bacaan interpretatif dari Firman Tuhan.la mencontohkan, YesusKris- 
Lutfi Maulida, Siti Nurmajah : Relasi Wahyu Dalam Tiga Agama Samawi (Kajian

tus,sebagai Firman Allah yang ber berinkarnasi, adalah homolog dengan Mushaf dalam representasi Muslim dan ke Penulisan sepuluh Taurat dalam tradisi Yahudi.Pendapat Arkoun ini menarik dan bisa dikatakan berbeda dan keluar dari pakem umum (anomali). Gagasan ini menjadi angin segar dalam diskursus wahyu dalam ranah studi antar agama. Guna memahami karyanya, penulis berupaya memusatkan pada aspek dekonstruksi dari kajian Arkoun terhadap teks dan konteks sejarah. Metode sejarah yang digunakan Arkoun adalah salah satu perpaduan dari beberapa ilmu sosial Barat Modern yang direkaysa oleh para pemikir pasca strukturalisme Prancis,seperti De Sausser (linguistic), Levi-Strauss (antrpologi), Michel Foucault (epistemeologi), dan Derrida (grammatologi).Arkoun pula tidak berhenti dalam teks klasik pening galan para ilmuwan, namun ia juga secara jelas mempertanyakan dan merambahi teks suci.

Pembacaan wahyu sejauh ini dilakukan secara parsial dan cenderung bersifat eksklusif. Parsial dan eksklusif di sini berarti bahwa wahyu hanya dipahami sebatas pada kekelompok keagamaan tertentu saja. Masing-masing agama memiliki klaim kebenarannya sendiri-sendiri. Dilihat dari perspektifnya yang memandang wahyu tidak hanya dari kacamata Islam saja,tetapi juga mempertimbangkan relasinya dengan dua agama pendahulu Islam. Artikel ini akan mengulas lebih jauh tentang bagaimana sebenarnya gagasan

Arkoun mengenai wahyu? Serta bagaimanakah implikasinya terhadap dialog antara agama samawi tersebut? Guna menjawab rumusan masalah pertama, penulis akan menggunakan metode deskriptif-analitik-interpretatif.
Untuk menjawab rumusan masalah kedua,penulis menggunakan pende katan analitik eksploratif. Tulisan ini secara singkat akan membincang konsep wahyu dan relasinya dalam tiga agama samawi melalui perspektif Arkoun, mencakup latar, kemunculan, dan beberapa implikasinya terhadap interaksi dan kemungkinan terbuka nya eksklusivitas pembahasan tentangnya dalam tiga agama tersebut. Melalui gagasan Arkoun inilah,konsepsi tentang wahyu kiranya dapat menjadi pembuka bagi dialog di antara ketiga agama samawi dan menepiskan pakem eksklusivitas pembacaan atasnya.

Peta Pemikiran Mohammed Arkoun. Mohammad Arkoun merupakan seorang filsuf Islam modern. Putra Algeria ini telah menghasilkan lebih dari 100 karya baik dalam bentuk buku makalah,maupun artikel.Mayo ritas karyanya berbahasa Prancis yang kemudian diterjemahkan kedalam Bahasa Arab dan bahasa lainnya. la dikenal sebagai sosok pemikir Islam yang produktif dan berani.Pengaruh gerakan poststrukturalis Prancis amat kentara dalam berbagai karyanya.

Karya-karya Arkoun sendiri amatlah banyak dan meliputi berbagai bidang kajian. Namun di sini hanya akan menyebutkan karyakaryanya yang berkaitan dengan kajian Islam pada umumnya. Secara garis besar pemikiran Arkoun cenderung filosofis.Terutama dalam bukunya The Unthought in Contemp orary Islamic Thought (Saqi Books, 2002), Islam: to Reform or to Subvert? (Saqi Books,2006), Traduction Francaise Avec Introduction et Notes du Tahdib al-Akhlak yang merupakan tulisan tentang etika atau terjemahan Kitab Tahdib al-Akhlak karya Ibnu Miskawaih. Ada pula karyanya yang 
berjudul Rethinking Islam: Common Question,Uncommon Answer,memuat sekitar dua puluh empat pertanyaan umum, namun dalam menjawabnya, Arkoun menggunakan narasi yang berbeda dari pakem pada umumnya.Arkoun juga menuangkan pemikirannya di ranah kajian al-Qur'an, seperti terlihat dalam karyanya Lectures $d u$ Coran (pembacaan-pembacaan al-Qur'an), Discours Coranique et Pensee Scintifique (wacana al-Qur'an dan pemikiran ilmiah), al-Quran min alTafsir bil Mauruth, dan satu artikelnya berjudul The Notion of Revelation: From Ahl al-Kitab to The Societies of The Book.

Mohammed Arkoun memiliki konsen terhadap kajian "Kritik atas Akal/Pemikiran Islam", di mana metode historis modern menjadi pisau analisis utamanya. Hal ini dapat dilihat dalam bukunya yang paling fundamental, Pour de la Raison Islamique (menuju kritik akal Islam). Buku tersebut awalnya diterjemahkan ke dalam Bahasa Arab dengan judul Naqdu al-Aqli al-Islamiy, kemudian diterjemahkan lagi dengan judul Tarikhiyyatu al-Fikri al-Arabiy alIslamiy (historisitas pemikiran Arab Islam). Buku ini juga telah diterjemahkan ke dalam Bahasa Indonesia dengan judul Nalar Islami dan Nalar Modern: Berbagai Tantangan dan Jalan Baru.

Ada pula karyanya, La Pensee Arabe (Pemikiran Arab) yang juga telah diterjemahkan dalam Bahasa Indonesia dengan judul Pemikiran Arab. Selain itu, ia juga memiliki kumpulan essay berjudul Essais sur La Pensee Islamique (esai-esai tentang pemikiran Islam). la juga berkolaborasi dengan salah seorang pemikir Prancis bernama Louis Gardet. Karya mereka adalah L'Islam,
Hier, Demain yang juga telah diterjemahkan ke dalam Bahasa Indonesia dengan judul Islam Kemarin dan Hari Esok. Karya yang membahas gagasan Arkoun di bidang politik antara lain adalah tulisan dari Muhammad Riqza Muqtada. Tulisan tersebut berjudul Utopia Khilafah Islamiyyah: Studi Tafsir Politik Mohammed Arkoun, terbit dalam Jurnal Theologia Volume 28 Nomor 1 tahun 2017 (Muhammad Riqza Muqtada,"Utopia Khilafah Islamiyyah:Studi Tafsir Politik Moha mmed Arkoun", Jurnal Theologia, Vol. 28 No. 1, 2017). Di sektor ini ada pula karya dari Yunus Rahawarin yang berjudul Membaca Pemikiran Arkoun tentang Etika Politik Islam. Artikel ini terbit pada Jurnal al-Fikr Volume 20 Nomor 1 tahun 2016.

Arkoun berupaya untuk me mbaca teks klasik sebagai proses pencari makna lain yang tersembunyi didalamnya, oleh karenanya untuk menuju rekontruksi (konteks) tidak lepas pada tahap kajian dekontruksi (teks) yang terbaca. Beberapa artikel yang membahas pemikiran Arkoun di ranah ini, diantaranya ialah karya Zaelani yang berjudul "Reskontruksi Tradisi Islam (Pemikiran Mohammad Arkoun Tentang Sunah)", dimuat dalam Jurnal Ushuluddin (Zaelani, Reskontruksi Tradisi Islam,Jurnal Ushuluddin,Vol.18,No.2,Tahun 2012 ).Karya berikutnya dari Muhammad Solikhin dan M.Fadholi,berjudul'Kritik Arkoun atas Epistemologi Islam" dalam Jurnal Kajian Keislaman.

(Muhammad Solikhin, M. Fadholi, "Kritik Arkoun atas Epistemologi Islam", Jurnal Kajian Keislaman, Vol. 7, No, 1 Tahun 2018).

Kemudian buah karya Az-Zahari berjudul "Pemikiran Fazlur Rahman dan Mohammad Arkoun" yang terbit pada Jurnal Studi Agama dan 
Lutfi Maulida, Siti Nurmajah : Relasi Wahyu Dalam Tiga Agama Samawi (Kajian

Masyarakat (Az-Zahari, Pemikiran Fazlur Rahnman dan Arkoun, Jurnal Studi Agama dan Masyarakat, Vol. 12, No. 2, tahun 2016). Artikel tersebut mengomparasikan pemikiran Fazlur Rahman dengan Mohammed Arkoun dalam hal pembaharuan kajian agama. Berikutnya karya Ahmad Syafi'i berjudul "Arkoun dan Kritik Nalar Islam". (Ahmad Syafi'i, "Arkoun dan Kritik Nalar Islam", Jurnal Vol. 10, No. 2, tahun 2015). Siti Rohmah Soekarba turut meramaikan pengkajian di ranah ini dengan tulisannya, "Kritik Pemikiran Arab: Metode Dekonstruksi Mohammed Arkoun" yang terbit dalam Jurnal Wacana (Siti Rohmah, "Kritik Pemikiran Arab: Metoe Dekontruksi Muhammad Arkoun", Jurnal Wacana, Vol. 8, No. 1. Tahun 2006). Ada pula tesis karya Irwan Malik Marpaung berjudul "Kritik Terhadap 'Kritik Nalar Islam Arkoun'”. Artikel berjudul "Kritik Nalar Islam sebagai Metode ljtihad: Membahas Pemikiran Mohammed Arkoun", buah pikir dari Jamhari yang diterbitkan dalam JIA: Jurnal IImu Agama (Jamhari, Kritik Nalar Islam sebagai Metode ljtihad: Membahas Pemikiran Mohammed Arkoun", Jurnal Ilmu Agama Nomor 1 Tahun XIV, 2013). Ada sebuah tulisan yang mengulas tentang salah satuinstrument penting dalam gagasandekon struksi Arkoun.Tulisan tersebut ber judul "Fungsi Nalar Menurut Mohammed Arkoun", karya dari Fuadi dalam Jurnal Substantia Sebuah tulisan hasil kolaborasi antara Usman Khalil dan Abida Khan berjudul, "Islam and Postmodernity: M. Arkoun on Deconstruction"terbit dalam JoJournal of Islamic Thought and Civilization (Fuadi, "Fungsi Nalar Menurut Mohammed Arkoun". Tulisan ini kemudian terbit dalam Jurnal Substantia Volume 18 Nomor 1 pada
April 2016). Terdapat pula karya yang mengkaji tentang pemikiran Arkoun di bidang kebahasaan, seperti artikel dari Ismail Suardi Wekke, "Tinjauan Mohammad Arkoun tentang Bahasa Arab, Teks, dan Semiotika Al-Qur'an" dalam Jurnal al-Fikr. (Ismail Suardi Wekke, "Tinjauan Mohammad Arkoun tentang Bahasa Arab, Teks, dan Semiotika Al-Qur'an" dalam Jurnal alFikr Volume 17 Nomor Tahun 2013). Tulisan dari Ishak Hariyanto berjudul "Hermeneutka Alquran Muhammad Arkoun", dalam Jurnal El-Umdah. (Ishak hariyanto, "Hermeneutika AlQur'an Muhammad Arkoun”, Jurnal, el-Umdah, Vol. 1, No.2 Juli 2018).

Dalam ranah kajian keislaman pada umumnya, terdapat beberapa karya yang mengkajinya. Diantaranya adalah karya dari Baedhowi dalam Jurnal Episteme, berjudul "Islamologi Terapan sebagai Gerbang Analog Pengembangan Islamic Studies:Kajian Eksploratif Pemikiran Mohammed Arkoun".(Baedhowi,"Isla -mologi Terapan sebagai Gerbang Analog Pengembangan Islamic Stu dies:Kajian Eksploratif Pemikiran Mohammed Arkoun", Jurnal Episteme Vol. 12, No. 2, 2017). Berikutnya ialah karya dari Hajriyana, "Relevansi Pemikiran Mohammed Arkoun dedengan Pendidikan Islam" dalam Jurnal Syamil. ( Hajriyana, "Relevansi Pemikiran Mohammed Arkoun dedengan Pendidikan Islam", Jurnal Syamil Volume 6 Nomor 1, 2018).

Dari beberapa literatur pemi kiran, Arkoun memberi kontribusi menarik akan hal ini, pemahamannya pada sejarah revolusioner yang memproduksi peristiwa tentang Tu han dan ajarannya. Berpengaruh pada makna wahyu sebagai relasi agama samawi. Di agama Kristen, Wahyu adalah subjek menurut bebeberapa teolog, tidak pula 
melahirkan sikis emosional secara kolektif, apa lagi sampai pada reaksi kekerasan, seperti dalam masyarakat Muslim. Meskipun dinamika di setiap zaman memang berpengaruh, makna pemaknaan terhadap wahyu dapat berfungsi sebagai solusi dalam menyikapi sebuah perbedaan, hal ini ditekankan oleh Arkoun karena Wahyu tidak berhubungan dengan karakteristik subtansial, tetapi justru perbedaan dapat ditemukan dalam ritme sejarah evolusi di masyarakat seperti di Islam bagaimana syarat sebagai Muslim.

Pembahasan mengenai gagasan Arkoun tentang Wahyu dan bagaimana implikasinya terhadap dialog antara tiga agama samawi memang belum pernah dilakukan sebelumnya. Melalui pendekatan deskriptif analitik secara keseluruhan serta pertimbangannya terhadap aspek sejarah, analisis Arkoun bertujuan agar dialog antar agama dapat terealisasi, khususnya dalam pemaknaan Wahyu antar kepercayaan, hal ini menjadi pemikir luar biasa Arkoun untuk mewujudkan kacamata agama secara universal.

Problem Terminologi Wahyu.

Dalam Kamus Besar Bahasa Indonesia, wahyu merupakan petunjuk dari Allah yang diturunkan hanya kepada para nabi dan rasul melalui mimpi dan sebagainya (Tim Penyusun, Kamus Besar Bahasa Indonesia: 1989, hlm. 1005).

Dalam kamus digital MerriamWebster's Dictionary, berikut pengertian dari revelation ialah sebuah tulisan apokaliptik yang ditujukan kepada orang-orang Kristen awal Asia Kecil dan dimasukkan sebagai sebuah buku dalam Perjanjian Baru yang disebut juga apocalypse. Dalam ensiklopedia Man and His Gods: Encydopaedia of The
World's Religions, kata wahy dianggap memiliki sinonimitas dengan kata ilham. Dalam ensiklopedi tersebut, ilham memiliki makna menyebabkan menelan atau menelan, sebuah istilah Al-Qur'an yang menunjukkan wahyu Allah kepada manusia secara individu, sebagai kebalikan dari wahyu-Nya kepada manusia pada umumnya melalui pesan yang dikirim melalui para Nabi, wahy ( Edward Geoffrey Parrinder: 1971).

Umat Kristiani memiliki konsepsinya sendiri terkait dengan wahyu. Dalam Alkitab Terjemahan Baru, pada Perjanjian Baru, wahyu dinyatakan sebagai wahyu Yesus Kristus, yang dikaruniakan Allah kepadaNya, supaya ditunjukkanNya kepada hamba-hambaNya apa yang harus segera terjadi. Dan oleh malaikatNya yang diutusNya, la telah menyatakanNya kepada hambaNya Yohanes. (Wahyu, 1:1). Yohanes telah bersaksi tentang firman Allah dan tentang kesaksian yang diberikan oleh Yesus Kristus, yaitu segala sesuatu yang telah diihatnya. (Wahyu, 1:2), (Indonesian Bible Society: 1974, hlm. 7). Adolf Hauken SJ, dalam Ensiklopedi Gereja, wahyu dipahami sebagai wujud Tuhan yang memanggil manusia agar mengikuti bagaian dalam kehidupan Ilahi. Dalam Kitab Taurat, dalam Perjanjian Lama disebutkan bahwa wahyu ialah petunjuk bagi Tuhan yang diturunkan kepada pilihanNya, dalam hal ini Musa, bahwa wahyu ada untuk mengarahkan masyarakat. Apabila tiada wahyu, maka liarlah masyarakat. (Ratapan, 2.1:13), (Tim Penyusun, Ensiklopedi Gereja: 1993, hlm. 3132 ).

Abi Mandzur Jamaluddin Muhamad bin Mukarram al-Anshari, Lisan Al-Arab, Bulak: al-Thaba'atu 
Lutfi Maulida, Siti Nurmajah : Relasi Wahyu Dalam Tiga Agama Samawi (Kajian

Mashurah, tp tahun, wahyu atau alWahyu adalah al-lsyarah (sebagai isyarat), al-Kitab (Kitab suci), alArisalah (utusan), Ilahi/Tuhan atas kalam-kalamnya pada setiap perintah. Sebagaimana keteranggannya "Dan telah aku wahyukan sebuah isyarat, utusan, dan kitab suci sebagai wahyu." Menurut keterangan al-A'jaz "Sesampainya sebuah utusan mereka terima sebagai wahyu, dan apa yang telah dikehendaki ketika proses pewahyuan, seperti harumnya bungga Zahroh dengan sumerbaknya, maka apa yang telah diberikan terhadap rasul sebagai utusan-Nya, maka telah aku ciptakan seperti apa itu bentuk wahyu dan keselamatan." ( Ibn Manzur, Mu'jam Lisan al-'Arab fi Lughah, Kairo: Daar al-Hadis, hlm. 1885).

Dalam Muqoyisul Lugoh, wahyu adalah dari asal kata harfu al- wawi, harfu al-ha'i, dan harfu al-ya'i tiga huruf tersebut memiliki pengamalannya masing-masing. Yakni sebagai petunjuk atas pengetahuan yang tersembunyi atau selainnya dalam memperoleh pembelajaran, dan terbagi kedalam beberapa kata yakni, kata wahyun dimaknai sebagai isarat, sedang alwahya adalah kitab sebagai petunjuk, dan al-risalah adalah menunjukan sesuatu selain wahyu, al-wahiyun dimaknai dengan sebuh keputusan sedang al-waha adalah suara tuhan yang bergerak cepat. Jadi, wahyu tuhan yang dianugerahkan kepada manusia itu melalui tiga cara, pertama wahyu dengan arti mengilhamkan sesuatu pengertian dalam hati sebagai isarat, kedua, wahyu diartikan dengan balik tirai, maksudnya dengan cara kasyf yang berbisik atau berpindah dalam keadaan antara mimpi, dan ketidaksadaran, wahyu ini dapat diilhamkan pada selain nabi dan merupakan bentuk yang paling sederhana, ketiga, wahyu yang disampaikan oleh malaikan Jibril dalam bentuk kata-kata, wahyu ini tergolong dalam posisi tertinggi yang khusus diberikan kepada para nabi. (Abu Husian Ahmad bin Zakariya, Muqoyisul lugoh, Kairo: 2008).

Dalam Encydopaedia of Religion and Ethics, revelation memiliki makna kata yang berarti proses yang digunakan Tuhan untuk memberitahukan kepada manusia kebenaran yang ia butuhkan, atau untuk tubuh kebenaran yang telah diketahui Tuhan (James Hastings, Encydopaedia of Religion and Ethics, NYC: 1908, hlm. 745). Dalam The Oxford Dictionary of World Religions, kata wahyu disebut dengan wahy, yang memiliki makna untuk menyarankan, letakkan sesuatu dalam pikiran seseorang (John Bowker, The Oxford Dictionary of World Religions, NYC: 1997, hlm. 1031).

Pembacaan atas wahyu sejauh ini dilakukan secara eksklusif. Di mana tiap agama memiliki konsepsinya sendiri tentang wahyu. Masing-masing agama memiliki klaimnya sendiri bahwa mereka ialah agama yang paling legitimate. Namun secara umum, pemaknaan tentang wahyu memiliki kurang lebih tiga unsur, yakni pertama bahwa ia adalah suatu petunjuk, pedoman hidup, atau pesan Ilahiyah. Kedua, ia pasti berasal dari Tuhan. Keriga, dalam proses penyampaiannya kepada umat manusia, terdapat seorang utusan atau manusia yang terpilih sebagai penyampai wahyu.

Wahyu dalam Semesta Pemikiran Arkoun. 
Arkoun berangkat dari dua surah al-Qur'an berikut ini dalam memulai kajiannya tentang wahyu:

"Dan tidaklah patut bagi seorang manusia bahwa Allah akan berbicara kepadanya kecuali dengan perantara wahyu atau dari belakang tabir atau dengan mengutus utusan (malaikat) lalu diwahyukan kepada nya dengan izin-Nya apa yang Dia kehendaki.Sungguh, Dia Maha tinggi, Mahabijaksana.Dan demikianlah Ka Kami wahyukan kepadamu (Muha mmad) ruh (al-Qur'an) dengan perintah Kami. Sebelumnya engkau tidaklah mengetahui apakah Kitab (alQur'an) dan apakah iman itu, tetapi Kami jadikan al-Qur'an itu cahaya, dengan itu Kami memberi petunjuk siapa yang Kami kehendaki di antara hamba-hamba Kami. Dan sungguh, engkau benar-benar membimbing (manusia) kepada jalan yang lurus." (QS.Asy-Syura:51-52)(Tim Penyusun Al-Qur'an Cordoba Special for Muslimah,(PT. Cordoba Internasional Indonesia: 2016, hlm. 488-489).

"Ha Mim. Demi Kitab (al-Qur'an) yang jelas. Kami menjadikan al-Qur'an dalam bahasa Arab agar kamu mengerti. Dan sesungguhnya alQur'an itu dalam Ummul Kitab (Lauh Mahfuz) di sisi Kami benar-benar bernilai tinggi dan penuh hikmah. Maka apakah Kami akan berhenti menurunkan ayat-ayat (sebagai peringatan) al-Qur'an kepadamu, karena kamu kaum yang melampaui batas?" (QS. Az-Zukhruf: 1-5) (Bandung: 2016, hlm. 489).

Pada dua ayat tersebut,Sesu ngguhnya Arkoun tidak 'membaca' secara panjang lebar, namun hanya menyebutkan bagaimana perincian al-Qur'an atas mekanisme wahyu itu. Pada dasarnya, dari ayat-ayat tersebut memang secara lafzi, dan tekstual tidak diberikan makna atau tafsirannya oleh Arkoun. Sehingga dalam penafsirannya itu, terkesan tidak berbeda dengan para pemikir lain yang bukan mufasir. Karena metode pembacaan al-Qur'an Arkoun (untuk sementara ini) tidak dalam bentuk ayat per-ayat (tahlili), tapi lebih dekat pada 'tematik' dan surat per-surat, misalnya pembacaanya terhadap QS. al-Fatihah dan al-Kahf, atau yang tematik yaitu tentang Haji ( Mohammed Arkoun, Berbagai Pembacaan al-Qur'an. terj. Machasin, Jakarta: 1997, hlm. 111).

Namun demikian, dalam beberapa tulisannya Arkoun mema parkan tentang wahyu,baik perspe ktif al-Qur'an ataupun dalam perspektif yang lainnya, seperti akan dibahas di sini.Ketika kita membicarakan wahyu bersama Arkoun, sesungguhnya kita tidak dapat melepaskannya dari 'pembacaan' Arkoun sendiri tentang al-Qur'an. Maksudnya adalah al-Qur'an yang telah menjadi al-Mushaf (dosed official corpus). Oleh karenanya sampai pada batas ini, penting untuk diperhatikan terlebih dahulu tentang 'bacaan' Arkoun tentang al-Qur'an atau Mushaf.

Dalam sejumlah ayat, kata Arkoun, penekanannya terdapat pada kebutuhan Nabi untuk menyesuaikan bacaan ayat-ayat, sesuai dengan tilawah sebagaimana yang nabi dengar sendiri. Beberapa Orientalisfilologis berpendapat bahwa kata alQur'an, memiliki asal-usul Syiria atau Hebrew, namun pengamatan mereka itu -lanjut Arkoun- tidak memodifikasi pengertian (makna) yang dituntut oleh konteks Qur'anik sendiri. Jadi ide dasar al-Qur'an, menurut Arkoun adalah ide tilawah yang sesuai dengan suatu khitab (wacana lisan) yang didengar (masmu'), bukan dibaca (maqru'). Sampai di sini, 
Lutfi Maulida, Siti Nurmajah : Relasi Wahyu Dalam Tiga Agama Samawi (Kajian

Arkoun 'membaca' dan membedakan antara al-qur' an dan al-wahy secara etimologis (lafz:i). Sehingga yang perlu diperhatikan dalam 'pembacaan' Arkoun tersebut, bahwa wacana al-Qur'an (khitab qur'ani) adalah al-wahy itu sendiri tentu saja, ini agak berbeda dengan tanzjl-. Bahkan dikatakan Arkoun sendiri, bahwa ia lebih mengutamakan pengggunaan wacana al-Qur'an dibandingkan teks al-Qur'an, pada fase awal penyampaian ayat-ayat alQur'an di zaman Nabi Muhammad, hal ini bukan semata-mata persoalan linguis semiotis, tapi juga antropologis ( Mohammed Arkoun: 1997, hlm 205). Sedangkan secara definitif, Arkoun tidak bersedia memaparkan lebih jauh karena ia merasa khawatir akan menjadi bahan tertawaan, mengingat telah begitu banyak definisi mengenai hal tersebut. Namun terlepas dari kekhawatiran Arkoun tersebut, dalam suatu bagian di salah satu tulisannya, Arkoun menjelaskan bahwa al-Qur'an adalah sejumlah makna potensial yang diusulkan kepada seluruh manusia. la juga mengatakan bahwa al-Qur'an adalah sebuah teks terbuka yang tak satupun penafsiran dapat menutupnya secara tetap dan ortodoks. ( Mohammed Arkoun, "The Notion of Revelation: From Ahl-Kitab to The Society of The Book", dalam Die Welt des Islams, XXVIII, Inggris: BRILL, 1988: hlm, 63).

Hal ini sesuai dengan paparan Arkoun dalam La Pensee Arabe. AlQur'an adalah sebuah korpus yang selesai, artinya benar-benar terbatas dalam jumlah ujaran yang membentuknya, sudah selesai baik dalam bentuk pengungkapannya maupun dalam bentuk isinya. Setelah korpus itu selesai, juga terbuka, dengan kata lain, teks al-Qur'an mengatakan sesuatu, melakukan suatu komunikasi, dan 'membuat berpikir', tidak peduli bagaimanapun keadaan wacana yang di dalamnya pembacaan itu terjadi. Dan maksudnya ujaran-ujaran, adalah kenyataan bahwa al-Qur'an telah dan masih merupakan sebuah 'perkataan' sebelum menjadi teks tertulis ( Mohammed Arkoun: 1997, hlm. 205). Arkoun menolak pendirian bahwa al-Qur'an sebagai hal yang serba transenden, tanpa hubungan apa pun dengan sejarah manusia yang konkrit dan Arkounjuga menolak pendirian yang mereduksi al-Qur'an hanya pada gejala historis semata. Melihat semua itu, Arkoun mengajak kita sebagai pembaca untuk 'membaca' al-Qur'an menurut aturan sebagai berikut: ( Mohammed Arkoun, "The Notion of Revelation": 1988, hlm. 87).

1. Mengangkat makna dari apa yang disebut dengan sacra doctrina ( ajaran suci) dalam Islam dengan menundukkan teks al-Qur'an dan semua yang dalam sejarah pemikiran Islam telah berusaha untuk menjelaskannya

2. Menetapkan suatu kriteria yang di dalamnya akan dianalisis motif yang dapat dikemukakan oleh kecerdasan masa kini, baik untuk menolak maupun mempertahankan konsepkonsep yang dipelajari

Sesungguhnya aturan,aturan tersebut merupakan suatu metode yang dapat diterapkan pada semua teks doktrinal besar. Oleh karena itu, untuk 'pembacaan' ,nya, Arkoun mengatakan bahwa mau tidak mau mesti mencakup tiga kecenderungan sebagai berikut:

1. Linguistis yang memungkinkan kita untuk menemukan keteraturan dasar di bawah ketakteraturan yang tampak 
2. Antropologis, yakni mengenali bahasanya dalam al-Qur'an bahasanya yang bersusunan mitis

3. Historis yang di dalamnya akan ditetapkan jangkauan dan batasbatas tafsir logika, leksikografis dan tafsir-tafsir imajinatif yang sampai hari ini, dicoba oleh kaum muslimin

Dari berbagai penjelasan yang telah dipaparkan Arkoun itulah, kita dapat melihat bahwa nampaknya Arkoun berusaha agar tetap mempertimbangkan wahyu sebagai sebuah gejala kultural, historis, semiotis (termasuk linguitis) dan antropologis ( Mohammed Arkoun, Kritik Konsep 'Reformasi Islam, dalam Dekonstruksi Syari'ah (II) Kritik Konsep Penjelajahan Lain, terj. Farid Wajidi, Yogyakarta: 1996: hlm. 21).

$$
\text { Dalam perspektif Arkoun }
$$

sendiri, "Wahyu dalam al-Qur'an" pertama-tama adalah hasil dari pembuktian linguistik, struktur sintaksis, semantik, dan semiotika diskursus al-Qur'an, yang menyediakan satu ruang komunikasi secara total diartikulasikan untuk mengutarakan pemikiran (gagasan) dan isi wahyu tersebut. Untuk menjelaskannya, Arkoun mengambil contoh pada QS. al-'Alaq. Dalam membaca surah ini, Arkoun menyatakan bahwa Allah 'kelihatannya' (appears) sebagai pelaku sentral, mengatur tata bahasa (grammatically) dan semantik seluruh wacana.

\section{Mengungkap Relasi Wahyu dalam Tiga Agama Samawi Melalui 'Masyarakat Kitab'.}

Arkoun melihat bahwa dalam al-Qur'an terdapat beberapa umat sebelum (umat) Muhammad yang pernah menerima wahyu, yang disebut dalam istilah ahl al-kitab. "Orang,orang Kitab" yang telah disebutkan al-Qur'an itu lebih sempit, daripada pengertian "Masyarakat Kitab", yang dikatakan Arkoun lebih luas dan kompleks ( Mohammed Arkoun, "The Notion of Revelation": 1988, hlm. 86). Arkoun memaparkan bahwa ahl al-Kitab adalah orangorang Yahudi dan Nasrani (Kristen) yang hidup berdampingan dengan Nabi Muhammad di Makkah dan Madinah. Mereka adalah umat pemilik wahyu yang lebih awal dan orang,orang beriman, yang juga dikasihi Allah sebagaimana orang,orang Muslim, yang telah menerima wahyu barunya. Namun disebutkan juga, bahwa sebagian mereka menentang Muhammad sebagai seorang Nabi, dan menolak untuk menerima al-Qur'an sebagai wahyu, firman Allah yang terakhir. Berkaitan dengan hal tersebut, Arkoun menyebutkan:

1. Mereka adalah sasaran Kitab, meski mereka menolak bahwa hal itu dari 'Kitab'

2. Kitab diidentifikasi sebagai alQur'an, sebelum menjadi Mushaf, yang pada akhirnya disatukan dengan 'Kitab'

3. Orang-orang Islam diintegrasikan ke dalam komunitas spiritual, yang disebut ahl al-Kitab sesuai dengan definisi baru yang diberikan al-Qur'an 4. Pada Q.S. At-Taubah ayat 29, terdapat pemisahan yang tegas antara orang Islam dan ahl al-Kitab yang berarti Yahudi dan Kristen, yakni telah membengkokkan (tahrif) Kitab Injil dan harus membayar pajak 5. Terdapat pembatasan yanmg lebih ketat yang ditetapkan antara $a h l$ al-Kitab, yakni mereka yang tercerahkan dengan pengetahuan ('ilm) yang terdapat di dalam Kitab, dan orang-orang pagan (ummiyun, jahiliyyun) yang sama sekali tidak bersentuhan dengan 'ilm 
Lutfi Maulida, Siti Nurmajah : Relasi Wahyu Dalam Tiga Agama Samawi (Kajian Terhadap Pemikiran Mohammed Arkoun)

Pada poin terakhir di atas, Arkoun seperti hendak menawarkan sebuah pembacaan baru atas ahl alKitab, selaras dengan konsep Masyarakat Kitab (the concept of The Societies of The Book). Di mana hal ini memungkinkan untuk memikirkan ulang konsep lama mengenai hal tersenut tanpa bergantung pada definisi polemis dan teologis yang hingga kini masih berlaku. Masyarakat yang dimaksud merujuk pada konsep semua metodologi dan problematika yang dipakai dalam ilmu-ilmu sosial, politik, humaniora saat ini. "Kitab", dalam hal ini, merujuk pada pendapat Arkoun, perlu dikaji ulang berkaitan dengan fenomena Kitab, yakni dengan memberlakukan pendekatan antrop ologis-kritis terhadap semua jenis organisasi kemasyarakatan.(Moham med Arkoun,"The Notion of Revelation": 1988, hlm. 85). Dengan demikian dapat diambil simpulan sementara bahwa ahl al-Kitab dalam pandangan Arkoun tidklah terbatas hanya pada umat Yahudi, Kristen, atau Islam saja, namun juga mencakup segenap masyarakat yang memiliki kitab yang diyakini memiliki karakteristik llahiyah atas kitab tersebut.

\section{Kesimpulan}

Melalui ulasan singkat di atas, Arkoun sebagai seorang pemikir Islam kontemporer asal Berber, Aljazair, yang bersentuhan dengan filsafat kontemporer di Eropa, ia berpendapat bahwa wahyu senantiasa hidup di tengah manusia sampai kapan pun. Mohammed Arkoun melihat bahwa Yahudi, Kristen, dan Islam merupakan kelompok masyarakat yang terbentuk dari Kitab dan diproduksi oleh dan atas dasar Kitab. la mengemukakan bahwa kunci dari revelations atau wahyu dalam hubungannya dengan tiga agama samawi ialah berasal dari berbagai bacaan interpretatif dari Firman Tuhan. Dalam perspektif Arkoun, Masyarakat Kitab tidaklah terbatas hanya pada umat Yahudi, Kristen, atau Islam saja, namun juga mencakup segenap masyarakat yang memiliki kitab yang diyakini memiliki karakteristik ilahiyah atas kitab tersebut. Sebagai suatu kelompok masyarakat yang memiliki wahyu ilahiyah berupa kitab, ulasan ini kiranya dapat menjadi pembuka untuk dialog antar agama tersebut, yang mana sejauh ini perbincangan tentang wahyu itu dilakukan secara eksklusif saja.

\section{DAFTAR PUSTAKA}

Arkoun, Mohammed, "The Notion of Revelation: From Ahl-Kitab to The Society of The Book", dalam Die Welt des Islams, XXVIII, Inggris: BRILL, 1988.

Mohammed, Berbagai Pembacaan al-Qur'an. terj. Machasin, (Jakarta: INIS, 1997.

Mohammed, Kritik Konsep 'Reformasi Islam, dalam Dekonstruksi Syari'ah

Kritik Konsep Penjelajahan Lain, terj. Farid Wajidi, Yogyakarta: LKiS, 1996.

Az-Zahari, Pemikiran Fazlur Rahnman dan Arkoun, Jurnal Studi Agama dan Masyarakat, Vol. 12, No. 2, tahun 2016.

Baedhowi, "Islamologi Terapan sebagai Gerbang Analog Pengembangan Islamic Studies: Kajian Eksploratif Pemikiran Mohammed Arkoun" , Jurnal Episteme Vol. 12, No. 2, 2017.

Bowker, John, The Oxford Dictionary of World Religions, NYC: 
Oxford University Press, 1997.

Fuadi, "Fungsi Nalar Menurut Mohammed Arkoun". Tulisan ini kemudian terbit dalam Jurnal Substantia Volume 18 Nomor 1 pada April 2016.

Hajriyana, "Relevansi Pemikiran Mohammed Arkoun dengan Pendidikan Islam", Jurnal Syamil Volume 6 Nomor 1, 2018.

Hariyanto, Ishak, "Hermeneutika Al Qur'an Muhammad Arkoun", Jurnal, el Umdah, Vol. 1, No.2 Juli 2018.

Hastings, James, Encydopaedia of Religion and Ethics, NYC: Chales Scribner's Sons, 1908.

Jamhari, Kritik Nalar Islam sebagai Metode ljtihad: Membahas Pemikiran Mohammed

Arkoun", Jurnal IImu Agama Nomor 1 Tahun XIV, 2013.

Khalil, Usman, dkk, "Islam and Postmodernity: M. Arkoun on Deconstruction", Journal of Islamic Thought and Civilization Vol. 3, No. 1, 2013.

Manzur, Ibn, Mu'jam Lisan al-'Arab fi Lughah, Kairo: Daar al-Hadis, 1885.

Muhammad Solikhin, M. Fadholi, "Kritik Arkoun atas Epistemologi Islam", Jurnal Kajian Keislaman, Vol. 7, No, 1 Tahun 2018.

Muqtada, Muhammad Riqza, "Utopia Khilafah Islamiyyah: Studi Tafsir Politik Mohammed Arkoun", Jurnal Theologia, Vol. 28 No. 1, 2017.
Parrinder, Edward Geoffrey, Man and His Gods: Encydopaedia of The World's Religions, Inggris: Littlehampton Book Services Ltd, 1971.

Rohmah, Siti, "Kritik Pemikiran Arab: Metode Dekontruksi Muhammad Arkoun", Jurnal Wacana, Vol. 8, No. 1. Tahun 2006.

Society, Indonesian Bible, Alkitab Terjemahan Baru, Jakarta:LAI, 1974.

Syafi'i, Ahmad, "Arkoun dan Kritik Nalar Islam", Jurnal Vol. 10, No. 2, tahun 2015.

Tim Penyusun, Al-Qur'an Cordoba Special for Muslimah, Bandung: PT. Cordoba Internasional Indonesia, 2016.

Tim Penyusun, Ensiklopedi Gereja, Jakarta: Yayasan Cipta Loma Caraka, 1993.

Tim Penyusun, Kamus Besar Bahasa Indonesia, (Jakarta: Balai Pustaka, 1989.

Wekke, Ismail Suardi, "Tinjauan Mohammad Arkoun tentang Bahasa Arab, Teks, dan Semiotika Al-Qur'an" dalam Jurnal al-Fikr Volume 17 Nomor Tahun 2013.

$\mathrm{XVI}$, Paus Benedictus, Jesus of Nazareth, USA: Doubleday Publishing, 2007.

Zaelani, Reskontruksi Tradisi Islam, Jurnal Ushuluddin, Vol. 18, No. 2, Tahun 2012.

Zakariya, Abu Husian Ahmad bin, Muqoyisul lugoh, Kairo: Daarul Hadist, 2008. 